The pathological report was as follows: The lower border of the liver extended from the left costal margin in the anterior axillary line to the crest of the ileum on the right, the notch being $15 \mathrm{~mm}$. to the left and $15 \mathrm{~mm}$. below the umbilicus. On the right it reached as high as the fourth rib. The liver was tense, firm, smooth, edges were rounded with the exception of the lower cdge of the right lobe, which was sharp. Color was pale yellow throughout, nowhere mottled. The cut surface was firm, pale yellow and greasy. The lobules were enlarged and their outlines indistinct.

Microscopic. - The liver cells showed marked variation in size and the normal outlines were much distorted. Fat almost entirely replaced the protoplasm of the cells, only an occasional nucleated crescent at the side of the cell remaining. There was no normal liver tissue left in any of the sections taken. The spleen was normal in size and color. The kidneys also appeared normal. The intestines were congested throughout, especially around "Peyer's patches," as seen through the peritoneal covering. No further examination of the organs was made.

Diagnosis. - Fatty infiltration of liver.

It would seem from the history that the baby was healthy at birth and continued to thrive for several weeks after being artificially fed. That somewhere, soon after July 1, it began to lose its appetite, vomit, and nothing special was noticed in its condition until just before leaving Chicago on Aug. 5, when it was thought the change to the seashore would revive it.

What condition could cause such a tremendous enlargement of the liver in an apparently healthy infant I do not know. Excessive fatty foods are said to give a child anorexia, vomiting and, incidentally, fatty liver. What the exact percentage of fat there was in this infant's food I have been unable to find out. On writing the attending physician in Chicago for the food formula, I got a reply that he had entirely forgotten how the food was modified. If the cream obtained in Chicago on which the baby was fed for some time was a very rich centrifugal cream, the diluted food might easily have contained as high as $5 \%$ fat, which would be too high for any baby, and might possibly account for the loss of appetite and liver enlargement which had probably been going on for a few weeks before leaving Chicago.

The cream obtained in New York was undoubtedly the cause of the baby's acute toxemia and the beginning of the end, but her liver had undoubtedly been enlarged long before this, as the enlargement of the liver was not especially marked after she was seen by the writer.

It hardly seems conceivable to me that a baby apparently so normal for two and a half months could have carried all this time a congenital liver of this character.

It does not seem to the writer that the acute toxemia would have killed the baby had the condition of the liver been normal, so that the ordinary nulabolic processes of the body could have been normally carried on, nor does it seem probable, had. the mother been well and nursed the baby, that it would have developed any such an extreme fatty condition of the liver. So it does seem as though the condition was caused by an ex- ternal cause, probably something in food, the character of which I have no idea unless it was excessive fat.

The extreme distress which the baby had seemed to be due to abdominal distention and pressure from the large liver, as on opening the abdomen it seemed as though it contained nothing but liver. There was never any jaundice about the infant.

This case is reported on account of the apparent rarity of such large livers in such small infants. Moderate degrees of fatty infiltration in older children, especially if ill-nourished, are very common, and it generally disappears when the child is put under good hygienic conditions and is built up.

It is hoped that others of greater expcrience will be able to throw some light on the cause in this case.

\section{THE PEDIATRIC SOCIETY AND THE GENERAL PRACTITIONER.*}

BY MICHAEL KELLY, M.D., FALL RIVER, MASS.

Encouragement to write this paper came from the recollection of a fact mentioned in the history of ancient Rome. Every year, at the beginning of the Saturnalia, there was one happy day when the relative positions of the members of the household were reversed: the masters occupied the places of the servants, and the servants played the rôle of masters, to the mutual enjoyment of all.

A medical practitioner for twenty-four years, I will endeavor to state from experience, or to suggest a few, at least, of the advantages which membership in the New England Pediatric Society possesses for a humble worker in the ranks. To present the subject in a manner worthy of it is entirely outside the power of a man of my professional history and training, and could be suitably accomplished only by one of the altruistic benefactors of the profession who conceived, organized and set in motion this much-needed, useful association.

It is needless to say, except for the purpose of argument, that the progress made by hospital and laboratory workers and observers in all departments of pediatrics is amazing and often bewildering to the general practitioner who has the time or the mental bent to read or study. It is quite impossible for the studious practitioner to keep pace with this progress. There is really a superabundance of new and reliable information. A textbook by the time it is four years old needs a thorough weeding, a thorough reconstruction, that it may contain only the cream of what is new. The general practitioner needs a somewhat similar overhauling and readjustment of his knowledge, a process which, for him, must be continual. The general practitioner realizes all this fully, and many of us who are not asso-

* Read at a meeting of the New England Pediatric Society, March 20, 1909 . 
ciated with a children's hospital staff, a medical school or a dispensary admit that we have not the courage to attempt to keep up with the rising tide of new pediatric knowledge. The large number of new words alone, the continually expanding volume of nomenclature, deter many from profitably reading the new textbooks or the finished scientific articles in the magazines and journals. A man of twenty, or ten, or much fewer years in practice, unless he is one of the busy few who always labor to keep abreast of the times, cannot read one of the newer contributions to the literature of pediatrics to-day without referring continually to his medical dictionary; and it does not take many years for even the medical dictionary to grow quite out of date. The old practitioner, and old in this connection does not mean many years, would need a glossary of the newer words at the end of each new work to enable him to read with comfort. Practitioners, subscribers for one or more medical journals, buyers of new medical books, men who studied Latin and Greek and are somewhat skilled in word roots, confess that they seldom attempt to read an article in one of the newer medical publications; it appears to them too much like hard work after a hard and fatiguing day's practice. All general practitioners are not in this class, but, unfortunately, it contains very many.

Because all general practitioners, and especially those who practice much amongst children, do not keep fully abreast of the newer medical knowledge and teachings, this knowledge has no effect upon their patients. The benefits of the most advanced scientific progress are as completely shut out from these children as if it did not exist. The practitioner is out of touch with the true spirit of the best modern practice, and, consequently, his numerous patients must suffer. These physicians may have read of the success of new modes of treatment, may have heard them described and recommended, but have not become familiar enough with them to employ them with confidence.

If there is an adequate remedy for this discouraging state of affairs, if there is a true specific, it should be applied with heroic activity. The remedy is found in membership by the general practitioner in the pediatric society and in regular attendance at its meetings. This remedy springs from direct contact with the original workers, men who are making the new scientific advances, the explorers, the men on the firing line of progress, the untiring pathfinders. We cannot fail to have a live, active interest in subjects which we hear discussed by the authors. This association will be to us a spur, stimulus, an inspiration to study continually; in this way unfamiliar terms will become familiar. Knowledge thus gained makes a deeper impression than that gleaned from books, and the need of the dictionary will be much less pressing.

That an extraordinarily large number of children to-day fail to receive all the benefits of modern medical knowledge is evident from a glance at the work done or left undone by too many medical school examiners. The medical school examiner has more clients than a physician upon a hospital staff or in a dispensary. His field of labor is still comparatively new, and but very imperfectly explored. A school inspector who appreciates the duties and opportunities of his position has a rare chance to make observations which will enlighten the profession and bring invaluable benefits to sick and well children. Yet how many inspectors appreciate their position at its true worth and endeavor to live up to it? Within the past three months statements have been published by persons whose business it was to investigate the methods of public school inspectors in three of the largest cities in New England. We find from these reports that several school teachers, or school principals, had never seen their inspector. Other reports show the methods of inspection as crude, perfunctory, imperfect. The benefits to pupils and community from many of the inspectors are small. This total neglect of serious duty, or clumsy performance of it, has happened, too, in the larger cities, where men are apt to be more careful. Following these statements from interested investigators comes the najve complaint from the doctors that their salaries are too small. Although a medical man deserves good remuneration for thorough medical school inspection, it is doubtful whether a larger salary would coax many men to do better work. It might simply increase their intellectual inertia. Few resign on account of salaries. They are out of touch with the demands of the position, and the first step obviously for them is association in the pediatric society with men who are seriously interested in studying the growth and development of children. School inspectors who continue to do poor work, or no work, and fail to avail themselves of membership in such an association, need the application of all the resources of psychotherapy.

My purpose in calling attention to the shortcomings of many medical school examiners is not to criticise those in whom these shortcomings exist, but to point out one of the chicf reasons why some of them err in this way. Many act thus solely on account of lack of touch with the importance and scope of their work. This branch was not taught in the medical school. It is one of the many additions to a medical education which the graduate by reading and study and hard work must acquire after his course at the school has been finished. Until the inspector has fully mastered this knowledge, and is prepared to labor in full sympathy with the letter and the spirit of the laws which demand the medical inspection of schools, he is not qualified to do his full duty toward conserving and improving the mental and physical efficiency of school children. When good, honest work has been done, and the inspector has demonstrated the value of his office, the question of salary will take care of itself.

The general practitioner, member of a school committee, frequently reflects no more glory on 
the profession than the medical school examiner. How many practitioners can we recall who have been conspicuous on such committees simply and solely as medical men? Schools built within the last ten or even five years are reported as having seats too large or too small or otherwise hygienically unsuitable for those who are to occupy them; the buildings are badly ventilated, and often without apparent necessity are located in low, damp, crowded or otherwise unsanitary localities. The hygienic defects of these schools pointed out by competent inspectors are many and impressive. Most of these defective schools were planned and accepted by school boards upon which were one or more general practitioners. The medical men failed to come fully up to the scientific needs of the situation when the schools were being constructed and furnished. In a large city many of whose schools present various hygienic defects, I have ascertained that almost continuously since 1872 medical men have been members of the school committee. In that city, criticisms are coming in of schools built and equipped within the last two or three years. The physicians upon that city's various school committees were neither better nor worse than many of their brethren in similar positions throughout New England. Neither were they the graduates of any one or any six medical schools. Occupying public or political positions, these physicians were rather politicians than real scientific, medical men. They impeded rather than facilitated the spread of sound pediatric knowledge.

A hospital for contagious diseases in a neighboring city which need not be named had, a few days ago, no night nurse for nineteen cases of diphtheria. The management say very truly that they do the best they can with the amount of money at their disposal. There is a fault somewhere, and the natural inference is that it rests with the taxpayers as represented by the finance committee or other political civic rulers, who refuse money to pay an adequate supply of nurses. This inference is crroneous, and places the blame where it does not primarily belong.

A hospital for contagious or communicable diseases is quite a modern institution. Intelligent laymon in city governments do not fully appreciate the need and the sanitary and economic advantages of such an institution, and they grudgingly appropriate money for its construction. It is difficult to convince them that any money spent for such a hospital is not money needlessly thrown away. The hazy ideas which many general practitioners, family physicians, have of the utility of contagious hospitals do not enlighten the city fathers and, consequently, many hospital patients ill with diphtheria, scarlet fever or other communicable disease needlessly suffer in various ways, and the real cause is the inertia or the lack of up-to-date medical knowledge of the body of medical practitioners in the locality. I do not accuse the few physicians whose duty it is to manage the hospital, but the entire local body of practitioners who should lead and enlighten the taxpayers.
From experience, I can testify that when citizens know what is best for their sick, and what is really needed to control the spread of disease, and protect the community, the money to pay all the bills will be promptly forthcoming. A clear and emphatic presentation of facts by earnest men who are fully alive to the latest scientific medical teachings will convince the city government and bring all needed supplies; the general practitioners who should be prepared to make this clear exposition of facts, and fail to do it, are the men to blame for scanty hospital supplies in nurses or otherwise.

It is not necessary to go into detail to show that the all-important subject of the milk supply is beset with the same difficulties and is amenable to the same successful treatment as the management of the contagious hospitals. In New England to-day, if the general practitioner cannot secure good cow's milk for his little patients, he has mainly himself to blame.

The daily advantages to the private patients of the member of the pediatric society I will not take time to point out. Neither will I do more than suggest the large amount of post-graduate instruction in the employment of remedies, at least, which many a general practitioner still unwittingly absorbs from the educated and persuasive gentlemen who continue to knock at our doors as representatives of the manufacturing druggist and chemist. These gentlemen are fully up to the times in their lines of business.

In conclusion, I would say that the nature of my subject, and the view of it which I have taken, necessitated that my remarks should be somewhat personal. I hold no brief for the Pediatric Society. I merely give credit to an institution which has helped me. Length of time in practice alone gives me a right to speak. After twelve years in practice I took two post-graduate courses in the Children's Hospital in this city. At the time of my studies in the hospital I realized that I had gone intellectually to sleep: Now, I felicitatc myself that I lived long enough to wake up. The experience is pleasant.

Almost annually sinee then $I$ have attended the meetings of the Pediatric Section of the American Medical Association. I have traveled a distance of fifty miles to every meeting of the New England Pediatric Society since its inception. I have found the trouble worth while. Full value has been received for the sacrifices made. This habit of attendance at meetings has given me a fair idea of the extent of pediatric progress, and also has convinced me that through no fault of the masters in pediatrics many children in New England still do not receive their full share of the benefits of pediatric science. That the fruits of the present advanced stage of medical science may be as far reaching and influential for all the children of New England as they ought to be, a closer alliance between the Pediatric Society and the general practitioner is of prime importance. To be enrolled in the society's list of membership is to be a matriculate in a post-graduate school. 